\title{
Adapting to climate change: an integrated biophysical and economic assessment for Mozambique
}

\author{
Channing Arndt $\cdot$ Kenneth Strzepeck • \\ Finn Tarp · James Thurlow $\cdot$ Charles Fant IV • \\ Len Wright
}

Received: 15 July 2010/ Accepted: 3 November 2010/Published online: 15 December 2010

(C) Integrated Research System for Sustainability Science, United Nations University, and Springer 2010

\begin{abstract}
Mozambique, like many African countries, is already highly susceptible to climate variability and extreme weather events. Climate change threatens to heighten this vulnerability. In order to evaluate potential impacts and adaptation options for Mozambique, we develop an integrated modeling framework that translates atmospheric changes from general circulation model projections into biophysical outcomes via detailed hydrologic, crop, hydropower and infrastructure models. These sector models simulate a historical baseline and four extreme
\end{abstract}

Edited by Golam Rabbani, Bangladesh Centre for Advanced Studies (BCAS), Bangladesh.

C. Arndt · F. Tarp

University of Copenhagen, Copenhagen, Denmark

e-mail: channing.arndt@econ.ku.dk

F. Tarp

e-mail: tarp@wider.unu.edu

K. Strzepeck

Joint Program on the Science and Policy of Global Change,

Massachusetts Institute of Technology, Cambridge, MA, USA

e-mail: strzepek@mit.edu

F. Tarp · J. Thurlow $(\bowtie)$

United Nations University, World Institute for Development

Economics Research, Helsinki, Finland

e-mail: thurlow@wider.unu.edu

\section{J. Thurlow}

International Food Policy Research Institute,

Washington, DC, USA

C. Fant IV · L. Wright

University of Colorado, Boulder, CO, USA

e-mail: chasfant@gmail.com

L. Wright

e-mail: len@clicslab.org climate change scenarios. Sector results are then passed down to a dynamic computable general equilibrium model, which is used to estimate economy-wide impacts on national welfare, as well as the total cost of damages caused by climate change. Potential damages without changes in policy are significant; our discounted estimates range from US\$ 2.3 to US \$7.4 billion during 2003-2050. Our analysis identifies improved road design and agricultural sector investments as key 'no-regret' adaptation measures, alongside intensified efforts to develop a more flexible and resilient society. Our findings also support the need for cooperative river basin management and the regional coordination of adaptation strategies.

Keywords Climate change - Biophysical and economic outcomes - General equilibrium modelling - Mozambique

\section{Introduction}

Mozambique is one of the poorest countries in the world. Despite notable progress since establishing peace in 1992, it faces many development challenges, including pronounced and widespread income poverty, low life expectancy and wide gaps in educational achievement (World Bank 2010b). Moreover, the country experiences high levels of climate variability and extreme weather events (i.e., droughts, floods and tropical cyclones). Droughts are the most frequent disaster, occurring every 3-4 years, and are a major constraint to development, since most of the country's population, especially the poor, reside in rural areas and rely on rainfed agriculture (Arndt et al. 2008). Mozambique also lies at the end of numerous transnational river basins, and so flooding in its deltas is a perennial threat to both farmers and infrastructure, especially when 
coupled with cyclonic storm surges. For example, more than half a million people (i.e., $3 \%$ of the total population) were displaced in 2000 when Mozambique experienced its worst flood in 50 years (World Bank 2010a). Finally, Mozambique's internal climate characteristics vary, with subtropical climates in the north and center of the country, and dry arid conditions in the south.

Current challenges of climate variability and weather risk are compounded by climate change, but little is presently known about how Mozambique will be affected and how it might adapt its policies to offset potential damages. Such impact assessments are difficult due to the inherent multidisciplinary, multi-sector and economy-wide nature of the analytical issues involved. In this paper we describe an integrated modeling framework that helps us translate a set of climate projections into biophysical and economic impacts. The model is the result of concerted research efforts over several years, combining biophysical and economic insights and projections, making it possible to analyze adaptation options within a coherent analytical framework. We apply this framework to Mozambique as an illustrative case, but the analytical framework can be applied to other countries.

In our analysis we rely on four climate change scenarios to reflect the full variation in global and local climate projections. Four direct impact channels are considered: energy, infrastructure, agriculture and coastal zones. Integrated river basin and water resource models help estimate streamflows and water availability, which then determine electricity generation. Floods predicted by the river basin models damage road infrastructure and raise maintenance costs. Detailed crop models capture yield deviations based on temperature and precipitation projections, and the results of a global model determine crop land losses due to rising sea levels. All these sector-level impacts are then passed to a dynamic computable general equilibrium (DCGE) model, which we use to estimate economy-wide impacts of climate change on socioeconomic variables, such as economic growth and welfare. To assess the economic cost of climate change we specify a baseline scenario that reflects development trends and policies and priorities in the absence of climate change, before finally moving on to simulating alternative adaptation responses and our discussion and conclusions.

\section{Integrated modeling framework}

Selecting climate change scenarios

There is considerable uncertainty over future climate change. Existing general circulation models (GCM) produce a wide range of future scenarios, especially when
Table 1 Climate changes in Mozambique in 2050 in the global and local scenarios

\begin{tabular}{lrrrr}
\hline & $\begin{array}{l}\text { Global } \\
\text { wet }\end{array}$ & $\begin{array}{l}\text { Global } \\
\text { dry }\end{array}$ & $\begin{array}{l}\text { Local } \\
\text { wet }\end{array}$ & $\begin{array}{l}\text { Local } \\
\text { dry }\end{array}$ \\
\hline Temperature change (Celsius) & & & & \\
$\quad$ North region & 1.8903 & 1.2270 & 1.4654 & 1.3745 \\
Center region & 1.8089 & 1.4021 & 1.4866 & 1.7759 \\
$\quad$ South region & 1.5782 & 1.5055 & 1.3625 & 1.6619 \\
Precipitation (\% change) & & & & \\
$\quad$ North region & 1.9398 & 3.4973 & 18.2335 & -22.4636 \\
Center region & -2.1171 & -6.9608 & 6.3606 & -27.1855 \\
$\quad$ South region & 1.4956 & -11.8690 & 15.5954 & -21.7373 \\
Climate moisture index & -0.6 & 9.3 & 33.0 & -58.6 \\
\hline
\end{tabular}

Source: own calculations using GCM results (CSIRO, NCAR, UKMO and IPSL)

examined at the country level (see Meehl et al. 2007). Moreover, apart from differences in the science of modeling global climate systems, there is also uncertainty over how the global economy will evolve in coming decades. This means that GCMs have to project a number of possible 'emission scenarios' based on different assumptions about future populations, technological advancements and global agreements to reduce carbon emissions.

In order to capture the full range of possible climate change realizations, we select four projections representing the total possible variation in precipitation outcomes at the global and country levels. The first two scenarios are the driest and wettest global projections chosen from all possible GCM/emission scenario pairings. We call these the 'global dry' and 'global wet' scenarios. However, the driest global projection is not necessarily the driest for Mozambique. Thus, in the second two scenarios we selected the driest and wettest projections for Mozambique (i.e., 'local dry' and 'local wet'). ${ }^{1}$ As shown in Table 1 , the national climate moisture indices (CMI) for the global scenarios are bounded by the more extreme outcomes of the local scenarios. In fact, the global dry projection raises the CMI for Mozambique, whereas the global wet scenario reduces it slightly.

All sub-national regions in Mozambique are expected to experience a $1-2^{\circ} \mathrm{C}$ increase in temperature by 2050 . This increase occurs under both wet and dry scenarios, and reflects the general consensus that temperatures will rise as a result of climate change (Meehl et al. 2007). Since our selection of climate change projections was based on precipitation, we expect to find greater variation in average precipitation changes in our four scenarios for Mozambique.

\footnotetext{
${ }^{1}$ GCM/emissions scenario pairings: Global Dry (CSIRO-MK3.0 a2); Global Wet (NCAR-CCSM alb); Local Dry (UKMO-HADGEM1 a1b); and Local Wet (IPSL-CM4 a2).
} 
However, at least some of the variation in precipitation reflects a lack of consensus among GCMs over precipitation projections, with these models often predicting opposite outcomes (Meehl et al. 2007). For example, average precipitation declines by 2050 under the local dry scenario, but increases under the local wet scenario. Differences across projections are even more pronounced at daily and monthly time scales. Overall, however, the GCMs suggest that Mozambique's climate will become hotter, and more variable and uncertain, as a result of climate change.

We use historical monthly climate data $\left(0.5^{\circ} \times 0.5^{\circ}\right)$ from the Climate Research Unit at the University of East Anglia for 1951-2000 to produce a baseline 'no climate change' scenario for each sub-national region. ${ }^{2}$ Our baseline scenario assumes that future weather patterns will retain the characteristics of historical climate variability. It should be noted that the purpose of the baseline scenario is not to predict future weather patterns, but to provide a counterfactual for the climate change scenarios. Therefore, taking the baseline scenario, we overlay a 10 -year moving average of the monthly deviations in temperature and precipitation predicted by the GCMs. This procedure produces four 'synthetic' climate projections containing both current climate variability (i.e., the historical baseline) and future climate changes. Later in this paper we will estimate the biophysical and economic impacts of climate change by comparing the results of each of the four climate change scenarios with those of the baseline scenario.

Linking climate change to biophysical and economic outcomes

The atmospheric projections for the baseline and climate change scenarios are translated into economic impacts via a series of specialized sector models. Figure 1 shows the flow of information through the integrated river basin and water resource models down to three sector models that estimate impacts on agriculture, energy and infrastructure. River basin models determine streamflows for water resource models, which then estimate water availability for hydropower models. The river basin model also predicts flood frequency and severity, which, together with precipitation and temperature, determines road damages in the infrastructure model. Climate projections directly affect agricultural production in the crop models. Finally, biophysical results are passed down to a multi-sector economic model that estimates the economy-wide impacts of climate change. We also include a fourth sectoral impact channel that determines land losses from sea-level rise.

\footnotetext{
2 This climate dataset is available online at http://www.cru.uea. ac.uk/cru/data.
}

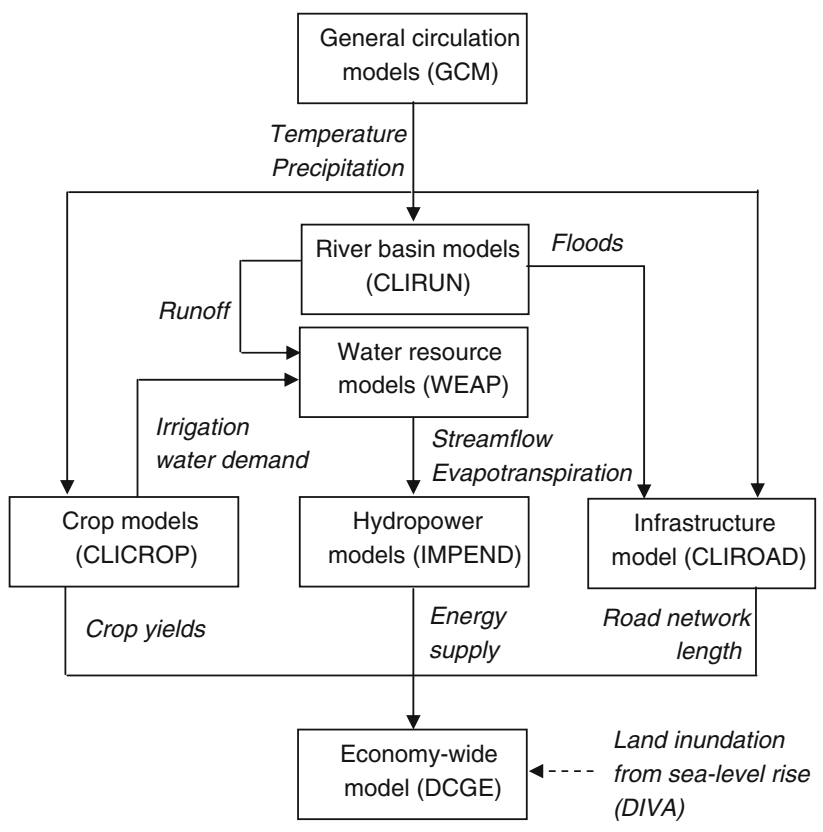

Fig. 1 Integrated modeling framework

Before describing the sector and economy-wide models, we first review the two water-related models.

Our 'CLIRUN' river basin model is an extension of a class of hydrologic models developed specifically to analyze the effects of climate change on runoff. Earlier applications of the model estimated single-layer lumped watershed runoff using mean monthly and annual rainfall (Kaczmarek 1993, 1996; Yates 1996). The current version of CLIRUN is extended to more accurately capture the tails of the runoff distribution. ${ }^{3}$ For this, the model adopts the two-layer approach of Gupta and Sorooshian $(1983,1985)$ that captures both quick and slow runoff. Runoff is modeled as a one-dimensional location at the mouth of a catchment. Water enters CLIRUN via precipitation and leaves via evapotranspiration and runoff. The difference between inflow and outflow is the change in soil or groundwater storage.

CLIRUN uses the modified Hargreaves method to estimate potential evapotranspiration (Hargreaves and Allen 2003), while actual evapotranspiration is a function of this potential and the soil moisture state (see Allen et al. 1998). The soil water model includes soil and groundwater layers, corresponding to quick and slow runoff responses to precipitation, respectively. The soil layer captures the effective precipitation that directly enters stream systems (i.e., a function of soil surfaces) as well as runoff via soil infiltration. Non-linear equations determine the volumes of water leaving the soil as runoff, percolating to groundwater

\footnotetext{
${ }^{3}$ For a detailed description and early application of the extended CLIRUN model, see Strzepek et al. (2008).
} 
and entering soil storage. The groundwater layer receives percolated water from the soil layer, and slow runoff is then a linear function of groundwater storage. CLIRUN is calibrated using historical runoff data from the Global Runoff Data Centre (GDRC), whose runoff fields is $\left(0.5^{\circ} \times 0.5^{\circ}\right)$ gridded estimates of average monthly runoff estimated by hybrid modeling/station data over 1960-1980. ${ }^{4}$ Comparing GDRC data with monthly station data for the 13 subcatchments of the Zambezi basin shows that it is representative at catchment level and accurate at the large spatial scales used in our integrated analysis. CLIRUN models are developed for all 98 catchment areas within Mozambique's 16 river basins. Catchment runoffs are then combined to produce total streamflow estimates for each river basin.

Modeling trans-boundary river basins is crucial since Mozambique lies downstream of most countries in Southern Africa. For example, Mozambique is the terminal point for the large Zambezi and Limpopo river basins, which cover $6 \%$ of Africa's total landmass and contain two of the continent's largest dams. Being furthest downstream provides Mozambique with good opportunities for water storage, hydropower and irrigation. However, it also makes the country vulnerable to flooding and changes in upstream reservoir policies. Therefore, the estimated streamflows from CLIRUN, along with the irrigation demands estimated from CLICROP (see below), are passed down to a water resource model based on the Water Evaluation and Planning System (WEAP) (Sieber and Purkey 2007). WEAP represents river basins' configuration of rivers and tributaries, their spatial and temporal hydrology, existing and potential major schemes, and various demands of water. WEAP evaluates interactions among municipal and industrial, irrigation and hydropower water demands under climate change. The model estimates impacts to irrigated agricultural yields and hydropower generation under each of the climate scenarios.

\section{Sector model 1: hydropower}

Hydropower generation relies on a combination of flow and elevation drop of water to generate electricity by turning turbines. There are four large-scale hydroelectric facilities in Mozambique, although the Cahora Bassa dam on the Zambezi River presently accounts for over $95 \%$ of production. Electricity generation currently exceeds domestic demand, making Mozambique a net exporter of electricity to neighboring countries.

We use a hydropower planning model called 'IMPEND' that was originally developed for Ethiopia (i.e., the Investment Model for Planning Ethiopian Nile Development) (see Block and Strzepek 2010). IMPEND is a water

\footnotetext{
$\overline{{ }^{4} \text { The GDRC }}$ dataset is available online at http://www.bafg.de.
}

accounting and optimization model that uses information on streamflow, evapotranspiration and reservoir attributes to determine energy generation and associated project costs. For the baseline scenario, IMPEND was calibrated to the Ministry of Energy's planned thermal, hydropower and renewable capacity expansion plan for 2010-2050 (Ministry of Energy 2009), as well as to streamflow and evapotranspiration results from CLIRUN and WEAP. IMPEND was then rerun for the four climate change scenarios, initially assuming no change in the baseline's expansion plan (i.e., deviations in hydropower generation are solely attributable to climate change and not to changes in dam construction).

\section{Sector model 2: infrastructure}

Infrastructure in Mozambique is particularly vulnerable to major floods, which frequently destroy roads and bridges. High temperatures also damage road surfaces and increase maintenance costs. We develop a new road infrastructure model called 'CLIROAD' that captures the effects of atmospheric conditions, including flooding, on road stocks and maintenance costs. About $80 \%$ of Mozambique's road network consists of unpaved roads, of which only $65 \%$ are in good condition (ANE 2007). Beyond programmed maintenance costs, about $10 \%$ of total government spending (i.e., recurrent plus investment) on roads is allocated to addressing washouts or other events not included in standard maintenance plans (World Bank 2010a).

CLIROAD tracks the life cycle of road vintages of different types (i.e., paved and unpaved, and primary, second and tertiary) and measures the annual dose-response relationship between climate and maintenance needs. More specifically, temperature and precipitation damage road surfaces and shorten their life span when climate stress exceeds engineering thresholds defined by the design standard to which a road vintage was built. ${ }^{5}$ Flooding damage depends on the severity of the flood (i.e., its 'return period' or RP). CLIROAD then calculates total maintenance costs (based on fixed unit costs), and this amount is removed from public road spending, whose growth rate is determined exogenously. Any remaining public transport funds are used to expand the network of paved and unpaved roads. Separate CLIROAD models are developed for each of the three sub-national regions. The models are calibrated to current road network data, expected road

\footnotetext{
$\overline{5 \text { Road stock }}$ data is from ANE (2007). In our analysis, the life span of a paved road declines for every $10 \mathrm{~mm}$ of rainfall and for a $3^{\circ} \mathrm{C}$ increase in maximum temperature (FDOT 2009). Precipitation- and temperature-related maintenance represents 4 and $36 \%$ of total maintenance costs, respectively (Miradi 2004). The base construction cost for paved roads is US\$ 0.5 million per kilometer (ANE 2007).
} 
investment plans, and to temperature and precipitation from the baseline and climate change projections. ${ }^{6}$

Sector model 3: agriculture

Agriculture is one of Mozambique's most important sectors, accounting for a fifth of national income and fourfifths of total employment (Arndt et al. 2008). The sector is dominated by small-scale farmers growing food crops (mainly maize and cassava) on rain-fed land without the use of modern inputs. Some export crops are produced on larger scale estates using irrigation. However, despite an irrigation potential of 3.3 million hectares, only 50,000 hectares are currently irrigated (mainly for sugarcane) (FAO 2009). Moreover, according to the Mozambican Ministry of Agriculture's capital expenditure plans, the amount of irrigated land will only double over the coming decades. ${ }^{7}$ Mozambique will thus remain vulnerable to climate change effects on rain-fed agriculture.

We use a generic crop model called 'CLICROP' to simulate the impact of the baseline and climate change scenarios on rainfed and irrigated crop yields and on irrigation water demand. CLICROP was specifically designed to capture climate change impacts since it models water stress from both insufficient and excess water supply (measured daily). ${ }^{8}$ The inclusion of waterlogging is an extension over simpler models, such as the FAO's CROPWAT (see Allen et al. 1998). Moreover, CLICROP's daily time scale allows it to capture the shorter but higher intensity rainfall and the overall drier conditions expected in Southern Africa as a result of climate change (Meehl et al. 2007).

The effects of the atmosphere (i.e., temperature and precipitation) are modeled indirectly in CLICROP via evapotranspiration (see Allen et al. 1998) and infiltration to the soil layers (based on soil properties). Soil moisture is calculated in each soil layer, including the moisture allowed to percolate into deep soil layers. Water balances and the upward flow of soil water are then measured. Crop yields are estimated using the approach of Allen et al. (1998). Waterlogging reduces yields via oxygen loss and

\footnotetext{
${ }^{6}$ Road network data were obtained from the national roads administration and corroborated with experts in road financing at the World Bank. Long-term road investment plans were being developed at the time of this writing and were not available in published form. A reasonable road investment plan was developed in collaboration with the team charged with developing the mediumterm fiscal framework in the Ministry of Planning and Development of Mozambique.

${ }^{7}$ Similar to roads, published long-term projections of irrigation expenditures are not available. Reasonable projections were drawn together based on discussions with knowledgeable government officials.

${ }^{8}$ For a detailed specification of CLICROP, see Fant (2009).
}

root growth hindrance (see Sieben 1964). We do not include the effects of $\mathrm{CO} 2$ fertilization.

Separate crop models were developed for the 14 major crops in each of the three sub-national regions of Mozambique. ${ }^{9}$ CLICROP was calibrated to information on soil parameters from the Harmonized World Soil Database (FAO/IIASA/ISRIC/ISS-CAS/JRC 2008) (e.g., field capacity, wilting point and saturated hydraulic conductivity) and historic crop yields and current irrigation patterns from the Ministry of Agriculture. Unlike the other two sector analyses, which use monthly data, CLICROP uses daily temperature and precipitation projections $\left(5^{\circ} \times 5^{\circ}\right)$ from the baseline scenario and four selected GCMs.

Sector model 4: coastal zones and sea-level rise

Flooding in Mozambique occurs most frequently in areas close to river basins, in low-lying areas and in areas with poor drainage. Mozambique is vulnerable to flooding since most of its coastline shares these properties. During 1958-2008, the country recorded 20 major flood events affecting more than 9 million people (INGC 2009). Mozambique is also vulnerable to storm surges since more than $60 \%$ of its population lives in coastal areas (World Bank 2009a). From 1994-2008 the northern, central and southern regions of the country were hit by two, three and two cyclones, respectively, with varying strengths at landfall (i.e., category 1-3) (INGC 2009). Moreover, the World Bank (2009a) suggests that, on average, Mozambique will be hit by cyclones three times a year. The country is therefore vulnerable to climate change impacts along its coastline.

Sea-level rise (SLR) is a global phenomenon. Accordingly, we draw on the results of a global climate change study (World Bank 2009b) that used the 'DIVA' model (i.e., dynamic and interactive vulnerability assessment). DIVA is an integrated model of coastal systems that assesses the biophysical impacts of SLR and socioeconomic development taking into account coastal erosion, coastal flooding, wetland change and salinity intrusion into deltas (see Hinkel and Klein 2009). DIVA uses information on land use, coastal population growth and economic growth to determine a range of outcomes, including lands permanently lost due to SLR. The World Bank (2009b) used DIVA to assess the risk and cost of SLR on the coast of Mozambique, but did not consider cyclonic storm surges. Therefore, our analysis of the economy-wide impacts of climate change also excludes cyclone damages.

\footnotetext{
${ }^{9}$ Crops include cassava, groundnuts, maize, millet, potatoes, sorghum, soybeans, sweet potatoes and wheat.
} 
Multi-sector economic model

Sector model results are passed down to a DCGE model of Mozambique, which estimates the economy-wide impact of the baseline and climate change scenarios, including spillovers from the four focal sectors to each other and to the rest of the economy (i.e., indirect or economy-wide linkages). Our DCGE model belongs to the structural neoclassical class of CGE models (see Dervis et al. 1982). ${ }^{10}$ Such DCGE models are well suited to analyzing climate change. First, they simulate the functioning of a market economy, including markets for labor, capital and commodities, and therefore can evaluate how changing economic conditions are mediated via prices and markets. Second, DCGE models ensure that all economy-wide constraints are respected, such as foreign exchange and factor resource supply constraints. These are crucial for long-run climate change projections. Finally, CGE models contain detailed sector breakdowns and provide a "simulation laboratory" for quantitatively examining how the individual impact channels of climate change influence the performance and structure of the whole economy.

Economic decision-making in the DCGE model is the outcome of decentralized optimization by producers and consumers within a coherent economy-wide framework. A variety of substitution mechanisms occur in response to variations in relative prices, including substitution between factors, between imports and domestic goods, and between exports and domestic sales. ${ }^{11}$ The Mozambique model contains 56 activities or sectors, including electricity generation, transport services and 24 agricultural subsectors (see McCool et al. 2009). Five factors of production are identified: three types of labor (unskilled, semi-skilled and skilled), agricultural land and capital. The agricultural activities and land are distributed across the three subnational regions (north, center and south). This sectoral and regional detail captures Mozambique's economic structure and influences model results.

Climate change affects economic growth and welfare in the DCGE model via four principal mechanisms. First, productivity changes in rain-fed agriculture are taken from CLICROP, and the DCGE then determines how much of the resources should be devoted to each crop given their profitability relative to other activities (i.e., "endogenous adaptation"). Profitability is here defined as the rental rate on fixed sector-specific capital. Second, the DCGE model directly incorporates fluctuations in hydropower production

\footnotetext{
${ }^{10}$ For a detailed specification of the generic DCGE model, see Thurlow (2004). For recent applications of the Mozambique model, see Arndt et al. (2008, 2010).

11 Production and trade function elasticities were drawn from Dimaranan (2006).
}

from IMPEND. River flows only affect crop production if the irrigated area available for planting exceeds the maximum potential area that could be irrigated given water availability constraints. Third, the length of regional road networks from CLIROAD is used in the DCGE model to determine the productivity of transport services. CLIROAD explicitly holds constant factors such as road width and the shares of investment allocated to different classes of roads. Implicitly, CLIROAD assumes that planners are equally effective at determining where new road construction should take place across climate scenarios. Given that these and other determinants of transport productivity are held constant, a shorter road network is assumed to lower transport productivity and increase the cost of moving goods between producers and consumers (see Arndt et al. 2000). Finally, the DCGE model incorporates the effects of SLR by reducing the total amount of cultivable land in each region by the land inundation estimates from DIVA. Other potential impact channels are recognized but not explicitly considered, such as health and tourism.

The long time frame over which climate change will unfold implies that dynamic processes are important. The recursive dynamic specification of our CGE model allows it to capture annual changes in the rate of physical and human capital accumulation and technical change. So, for example, if climate change reduces agricultural or hydropower production in a given year, it also reduces income and hence savings. This reduction in savings displaces investment and lowers production potential. ${ }^{12}$ Similarly, higher road maintenance costs imply less infrastructure investment and shorter road networks both now and in the future. Extreme events, such as flooding, also destroy infrastructure with lasting effects. Generally, even small differences in accumulation can cause large differences in economic outcomes over long time periods. Our DCGE model is well suited to capture these path-dependent effects.

\section{Results: climate change impacts}

\section{Baseline scenario}

In order to estimate the economic cost of climate change for Mozambique, it is necessary to first specify a baseline scenario that reflects development trends, policies and priorities in the absence of climate change. The baseline

\footnotetext{
12 Given our long-run focus, our macroeconomic "closure" assumes that changes in aggregate absorption are proportionally distributed across nominal private and public consumption and investment via distribution-neutral changes in savings rates (see Lofgren et al. 2002). Government savings are flexible, tax rates are fixed, and the real exchange rate adjusts to maintain an exogenously determined current account balance.
} 
provides a reasonable trajectory for growth and structural change of the economy from 2003 to 2050 that can be used as a basis for comparison.

Economic growth in the DCGE model is determined by rates of factor accumulation and technical change. For population and labor supply, we follow World Bank (2009b) and assume that Mozambique's population will continue to grow but at a decelerating rate (i.e., $2 \%$ today falling to $0.4 \%$ by 2050). We assume that the expansion of cultivated crop land will slow alongside unskilled labor, with growth in agricultural production increasingly dependent on the adoption of improved technologies rather than land expansion. As described earlier, the crop models use historical climate data to define year-on-year yield fluctuations in the baseline for each crop and region. Improvements in the education levels of Mozambique's workforce observed over the last decade are assumed to continue, with productivity rising faster for skilled and semi-skilled workers than for unskilled workers (i.e., at 2 and $1.5 \%$ per year, respectively, compared to $0.5 \%$ ). Baseline annual growth in hydropower generation and regional road networks are determined by the sector models using historical climate data. Under the above assumptions, the model shows how Mozambique's economy gradually develops, with agriculture's contribution to gross domestic product (GDP) falling from 26 to $16 \%$ during 2003-2050. Overall, per capita GDP grows at about $2 \%$ per year in the baseline, which, despite being a fairly modest long-run growth rate compared to current more rapid economic growth, significantly improves average household welfare.

Sector-level impacts

We first present the estimated biophysical impacts of climate change from the sector models. Table 2 reports deviations in average annual maize and cassava yields from the baseline for each climate change scenario for 2003-2050. These are 2 of the 14 crops modeled using CLICROP. It should be noted that the crop model's predicted yields are determined by daily temperature, precipitation and waterlogging, which makes direct comparisons with the atmospheric changes in Table 1 difficult. However, consistent with precipitation changes, the impact of climate change on crop yields is not always negative. For example, Southern cassava yields decline significantly in the local dry scenario, but increase in the local wet scenario. Yield impacts vary across crops, based in part on their physiological characteristics and growing periods. For example, Southern cassava yields decline but maize yields increase in the two global scenarios. Overall, the crop model results suggest that the impact of climate change on crop yields is worst under the local dry scenario, although some crops and regions will benefit in other climate change scenarios.

Table 3 reports the frequency of flood events of different severities predicted by the river basin models. For example, 31 floods with RPs of less than 2 (i.e., roughly a 'normal' year) occurred in the baseline scenario, whereas
Table 2 Changes in crop yields due to climate change for selected crops

Source: results from CLICROP

Table 3 Predicted frequency and severity of floods in the central region

A flood's 'return period' is a measure of its severity and expected frequency (e.g., an RP50 flood is a relatively severe 1-in-50 year event)

Source: results from CLIRUN

\begin{tabular}{lcccc}
\hline & \multicolumn{4}{l}{ Average change in yield from baseline, 2041-2050 (\%) } \\
\cline { 2 - 5 } & Global wet & Global dry & Local wet & Local dry \\
\hline Cassava & & & & \\
North region & 2.01 & -3.44 & -0.09 & -6.51 \\
Center region & -4.75 & -6.24 & -3.10 & -6.21 \\
South region & -9.36 & -3.27 & 0.36 & -3.20 \\
Maize & & & & \\
North region & 1.27 & -1.32 & -2.92 & -1.87 \\
Center region & 0.34 & 0.64 & -3.04 & -5.59 \\
South region & 3.49 & 6.37 & -4.36 & -3.95 \\
\hline
\end{tabular}

\begin{tabular}{llllll}
\hline \multirow{2}{*}{ Return period } & \multicolumn{5}{l}{ Number of years with floods of given return periods, 2003-2050 } \\
\cline { 2 - 6 } & Baseline & Global wet & Global dry & Local wet & Local dry \\
\hline $0-2$ & 31 & 21 & 17 & 32 & 34 \\
$2-5$ & 12 & 19 & 17 & 13 & 11 \\
$5-10$ & 0 & 1 & 4 & 0 & 0 \\
$10-20$ & 0 & 0 & 1 & 1 & 1 \\
$20-50$ & 3 & 3 & 1 & 0 & 1 \\
$50+$ & 2 & 4 & 8 & 2 & 1 \\
\hline
\end{tabular}


there were only two events with RPs of 50 or higher-one of which was the major flood in 2000. CLIRUN predicts only slight changes in flooding patterns for the local wet and local dry scenarios. This is partly because Mozambique lies at the end of large trans-boundary river basins, so floods are often determined by climate patterns in upstream countries. Indeed, the scenario with the highest frequency of severe floods is the global dry scenario. Although this scenario is dry from a global perspective, it is a wet scenario for the Southern African river basins affecting Mozambique. This is evident in Table 3, where the number of floods with RPs greater than 50 rises from two in the baseline to eight in the global dry scenario. Flooding from upstream basins is also more frequent in the global wet scenario, but is less severe in the local dry scenario.

Flooding is a major source of road network damages in the transport infrastructure model. Table 4 reports changes in the length of the national road network by 2050 relative to the baseline (see the 'without adaptation' column). The scenario with the most flooding (i.e., global dry) also has the largest decline in road stocks. However, the road network also contracts slightly in the climate change scenario with the fewest major floods (i.e., local dry). This is due to higher temperatures, that damage road surfaces and increase maintenance costs, thus reducing the funds available for new road development. Overall, climate change is expected

Table 4 Road infrastructure damages caused by climate change

\begin{tabular}{lcc}
\hline & \multicolumn{2}{l}{$\begin{array}{l}\text { Change in national road network length } \\
\text { relative to baseline, 2050 (\%) }\end{array}$} \\
\cline { 2 - 3 } & Without adaptation & With adaptation \\
\hline Baseline & 0.0 & 1.1 \\
Global wet & -16.1 & -9.0 \\
Global dry & -22.4 & -14.0 \\
Local wet & -11.9 & -4.0 \\
Local dry & -2.1 & 2.9 \\
\hline
\end{tabular}

Source: results from CLIROAD

Table 5 Changes in hydropower generation due to climate change

\begin{tabular}{cccccc}
\hline & \multicolumn{3}{c}{ Average annual production (gigawatt hours per year) } \\
\cline { 3 - 6 } & & \multicolumn{5}{c}{ Change from baseline (\%) } \\
\cline { 3 - 6 } \cline { 3 - 6 } Baseline & Global wet & Global dry & Local wet & Local dry \\
\hline $2003-2050$ & 22,245 & -2.50 & -0.35 & -5.81 & -7.97 \\
$2003-2010$ & 13,533 & 1.09 & 0.26 & -3.07 & -5.31 \\
$2011-2020$ & 17,391 & -2.35 & -0.55 & -7.36 & -6.62 \\
$2021-2030$ & 26,991 & -1.82 & 0.40 & -5.30 & -6.75 \\
$2031-2040$ & 26,087 & -3.94 & -0.62 & -8.08 & -7.26 \\
$2041-2050$ & 25,479 & -3.37 & -0.98 & -4.15 & -12.04 \\
\hline
\end{tabular}

Source: results from IMPEND to have a significant, negative impact on road infrastructure, especially under the wetter regional conditions of the global dry scenario.

Finally, Table 5 reports changes in hydropower generation from IMPEND. Production expands rapidly in the first 2 decades of the baseline due to planned dam investments, such as the Nphanda Nkuwa dam, which is due for completion in 2015 with capacity similar to Cahora Bassa. Such rapid increases in capacity far exceed domestic demand projections, so Mozambique remains a net energy exporter throughout the baseline. Moreover, even the large reduction in hydropower generation in the local dry scenario, where streamflows are lowest, is insufficient to reverse Mozambique's net exporting position. Climate change's impact on the energy sector is therefore unlikely to constrain urban or industrial expansion within Mozambique.

\section{Economy-wide impacts}

The DCGE model uses the sector results to estimate the economic impacts of climate change. The results of this economy-wide analysis are summarized in Table 6. We focus on changes in "absorption," which is the broadest measure of welfare in the economy. Absorption tracks an economy's use of goods for household consumption $(C)$, investment $(I)$ and government expenditure $(G)$. Absorption is closely related to GDP growth. Formally, absorption (A) is defined as $A=C+I+G$. Recalling that GDP $=C+I+G+X-M$, where $X$ is exports and $M$ is imports, we can write that $A=\mathrm{GDP}+M-X$. In other words, absorption is the volume of goods produced by the economy plus the goods that foreigners supply to the economy (imports) less the goods sent out to foreigners (exports). In the Mozambican context, the focus on absorption is preferred because large foreign investments have the potential to add significantly to GDP but little to absorption. For example, the country's large aluminum smelter, Mozal, accounts for $10 \%$ of national GDP, yet because it is export-oriented, capital intensive and profits are remitted, it adds little to national absorption. Similarly, if most hydropower revenues are repatriated to cover dam construction costs, then it too will have only a small effect on national welfare.

Table 6 reports average annual growth rates of real per capita absorption over the entire 2003-2050 simulation period. Climate change reduces absorption or national welfare in all four scenarios. The largest reduction is in the global dry scenario, which registers a 0.38 percentage point decline in absorption growth (i.e., from $2.12 \%$ in the baseline to $1.74 \%$ ). By contrast, the local dry scenario results in the smallest reduction in absorption. Again, it may seem counterintuitive that the driest global scenario produces worse results than the driest local scenario. 
Table 6 Economy-wide impacts of climate change

\begin{tabular}{|c|c|c|c|c|c|}
\hline & Baseline & Global wet & Global dry & Local wet & Local dry \\
\hline Average annual real per capita absorption growth rate, 2003-2050 (\%) & 2.12 & 1.85 & 1.74 & 1.91 & 2.03 \\
\hline Deviation from baseline & - & -0.27 & -0.38 & -0.20 & -0.09 \\
\hline $\begin{array}{l}\text { Average annual undiscounted value of absorption, 2046-2050 } \\
\text { (US\$ billions, } 2003 \text { prices) }\end{array}$ & 15.86 & 14.12 & 13.42 & 14.51 & 15.21 \\
\hline Deviation from baseline & - & -1.74 & -2.44 & -1.35 & -0.65 \\
\hline $\begin{array}{l}\text { Accumulated discounted deviation in absorption from baseline, } \\
2003-2050 \text { (US\$ billions, } 2003 \text { prices) }\end{array}$ & - & 4.93 & 7.42 & 4.40 & 2.29 \\
\hline Accrued during 2010s & - & 0.62 & 1.04 & 0.64 & 0.39 \\
\hline Accrued during 2020 s & - & 1.03 & 1.57 & 0.94 & 0.45 \\
\hline Accrued during 2030s & - & 1.45 & 2.07 & 1.20 & 0.53 \\
\hline Accrued during 2040 s & - & 1.77 & 2.48 & 1.36 & 0.67 \\
\hline Due to crop yields and sea-level rise & - & 0.36 & 1.21 & 0.94 & 1.61 \\
\hline Due to flooding and road damages & - & 4.56 & 6.21 & 3.42 & 0.63 \\
\hline Due to declining hydropower generation & - & 0.01 & 0.00 & 0.04 & 0.05 \\
\hline $\begin{array}{l}\text { Deviation in average annual real per capita GDP growth rate } \\
\text { from baseline, 2003-2050 (\%) }\end{array}$ & -0.27 & -0.38 & -0.20 & -0.08 & -0.27 \\
\hline Agriculture & -0.18 & -0.26 & -0.12 & -0.12 & -0.18 \\
\hline Industry & -0.38 & -0.53 & -0.29 & -0.09 & -0.38 \\
\hline Services & -0.24 & -0.34 & -0.18 & -0.08 & -0.24 \\
\hline North region & -0.15 & -0.27 & -0.15 & -0.11 & -0.15 \\
\hline Center region & -0.22 & -0.27 & -0.12 & -0.16 & -0.22 \\
\hline South region & -0.22 & -0.20 & -0.05 & -0.08 & -0.22 \\
\hline
\end{tabular}

Source: results from the DCGE model

However, as the river basin models showed, the global dry scenario is in fact a very wet scenario for Southern Africa as a whole. As discussed below, this causes flooding damages that dominate overall economic losses from climate change in Mozambique. Similarly, it might also seem counterintuitive that the global dry scenario, for being so wet, is in fact not the wettest local scenario. However, this highlights the importance of taking a regional perspective when assessing climate change impacts. In this case, it is climate patterns in upstream countries that determine major flooding in Mozambique rather than climate patterns within the country itself.

Climate change reduces average annual absorption growth rates by at most 0.38 percentage points. However, even small reductions in rates of growth over a 50-year period eventually accumulate and result in significant differences in absorption levels by 2050. Table 6 reports the average annual level of absorption during the 5-year period 2046-2050. In the worst performing global dry scenario, the level of total absorption is only $85 \%$ of baseline levels. Even in the best performing local dry scenario, absorption falls to $96 \%$ of baseline levels. This means that, by the midcentury, national welfare in Mozambique could be as much as $15 \%$ lower as a result of climate change.
We estimate the total economic cost of climate change, measured as the cumulative loss or deviation in national absorption from the baseline using a 5\% annual discount rate. In the global dry scenario, the total discounted cost throughout 2003-2050 amounts to US\$ 7.4 billion (measured in 2000 prices). This amount is roughly equivalent to Mozambique's GDP in 2003. Total losses in the local dry scenario still amount to US\$ 2.3 billion. Table 6 decomposes these costs and shows that climate change impacts become larger through time. For example, one seventh of the damages from climate change in the global dry scenario occur during the 2010s, while a third of the damages occur in the final decade of our analysis. This escalation of costs reflects the compounding effects of reduced accumulation rates, as well as the worsening impacts of climate change towards the middle of the century. It should be noted that most GCMs predict a pronounced aggravation of climate change impacts during the second half of the century. While the time horizon of our analysis ends in 2050, there is little doubt that, were the time frame extended, the tendency for later periods to exhibit progressively stronger impacts would certainly remain and likely strengthen.

A principal feature of the DCGE model is its ability to evaluate the relative importance of different sector impacts. 
Table 6 decomposes the costs of climate change into three channels: crop yields and SLR, transportation system and hydropower. ${ }^{13}$ The table shows the dominant role played by transport system disruption, principally, but not exclusively, as a result of flooding. As mentioned above, the global dry scenario is in fact a very wet scenario for the broader region, and so causes significant flooding. By contrast, the local dry scenario generates fewer floods and transport damages, but has a more adverse effect on agriculture.

The impacts of climate change on infrastructure are strong because they endure. A drought may reduce agricultural output dramatically during a particular cropping season, with strong implications for the welfare of households. However, in the following year, crop production typically returns to normal levels if rains return. An increase in the variance of agricultural production will have little impact on long run growth so long as underlying rates of factor accumulation and technical improvement remain relatively constant.

The same applies for hydropower. Reduced streamflow leads to reduced energy output. However, when streamflow returns, so does energy production. Hydropower also has limited impact on absorption in Mozambique because of the important role of foreign financing in dam construction. The model repatriates four-fifths of hydropower net revenues abroad in order to cover dam construction costs. While this provides a reasonable risk-adjusted return to investors, it also implies that hydropower investments have a muted impact on total absorption, at least over the repayment period.

Flood-induced destruction of infrastructure is different from the other impact channels because its effects endure. Once a road is washed away, its negative effect remains until the road is rebuilt. However, with constant resources allocated to roads, reconstruction of a section of road that is washed away due to heavy rainfall or flooding implies fewer resources available for construction of new roads or regular rehabilitation of existing roads. The large distances and dispersed nature of production in Mozambique reinforce the importance of the road network. Earlier analyses have highlighted the large differences between farm/factory gate prices and prices paid by final users (Tarp et al. 2002) as well as the substantial gains to the economy that can be obtained from reduction in these margins (Arndt et al. 2000). By implication, damages to road infrastructure increase the implicit distance between producer and final user, raising consumer prices and lowering producer

\footnotetext{
13 The impact of SLR via agricultural land losses is small and so is grouped with crop yield losses. Impacts may be larger were we to include climate change's effects on the frequency and severity of cyclones and storm surges, or damages to urban infrastructure.
}

earnings. Disruptions to the transport sector therefore have important economy-wide implications, well beyond the transport sector itself.

Finally, we consider the sectoral and regional impacts of climate change. This is shown in Table 6 as deviations in average annual real per capita GDP growth from the baseline. Note that in all scenarios, including the baseline, agriculture grows more slowly than either industry or services. Given the higher concentration of industry and services in the center and south, this translates into slower economic growth in the north. The DCGE model results indicate that all sectors and regions are negatively affected by climate change. The largest decline in growth rates relative to the baseline is in agriculture and in the north, where agriculture dominates the local economy. The large metropolitan center of Maputo in the south means that a larger share of this region's economy is relatively insulated from the direct effects of climate change. As such, the south experiences smaller declines in GDP than elsewhere in the country.

In summary, national welfare declines under all four of the selected climate change scenarios. The largest losses occur in the global dry scenario and, after discounting, amount to a total US\$ 7.4 billion over the period 2003-2050. Second, economic losses caused by climate change grow substantially over time, highlighting the importance of responding early to mitigate climate change and to adapting to new climate conditions. Finally, while agriculture is adversely affected by climate change, it is major flooding and the damage it causes to transport infrastructure that dominates overall welfare losses in Mozambique. Unlike agriculture, which directly contributes to economic growth, transport services have a more indirect impact on the rest of the economy, thus illustrating the advantages of our integrated sector and economy-wide analysis.

\section{Results: adaptation options}

In the previous section we measured the economic cost of climate change in terms of the damages it causes. However, the cost of adaptation is not necessarily equal to those damages. Moreover, it may not be economically sensible to direct adaptation resources towards damaged areas. For example, hard adaptation investments to protect coastal regions may prove more costly than the damages themselves. By contrast, soft adaptation options, such as rezoning vulnerable investments away from high risk areas, may prove more cost effective in the long run. In this section we examine selected adaptation options and use our integrated modeling framework to estimate their effectiveness in offsetting the costs of climate change.

The DCGE model captures some endogenous or 'autonomous' adaptation. If climate change adversely 
Table 7 Economy-wide impacts of alternative adaptation scenarios

\begin{tabular}{|c|c|c|c|c|c|c|}
\hline & \multicolumn{6}{|c|}{ Average annual real per capita absorption growth rate, 2003-2050 (\%) } \\
\hline & \multirow{2}{*}{$\begin{array}{l}\text { Baseline } \\
\text { scenario (1) }\end{array}$} & \multirow{2}{*}{$\begin{array}{l}\text { Climate change } \\
\text { scenario }(2)\end{array}$} & \multicolumn{4}{|c|}{ Adaptation scenarios } \\
\hline & & & $\begin{array}{l}\text { Transport policy } \\
(3=2+)\end{array}$ & $\begin{array}{l}\text { Agricultural extension } \\
(4=3+)\end{array}$ & $\begin{array}{l}\text { Irrigation investment } \\
(5=3+)\end{array}$ & $\begin{array}{l}\text { Education policy } \\
(6=3+)\end{array}$ \\
\hline Global wet & 2.12 & 1.85 & 1.93 & 2.23 & 1.96 & 2.23 \\
\hline Global dry & 2.12 & 1.74 & 1.81 & 2.12 & 1.84 & 2.12 \\
\hline Local wet & 2.12 & 1.91 & 1.97 & 2.27 & 2.00 & 2.28 \\
\hline Local dry & 2.12 & 2.03 & 2.05 & 2.33 & 2.08 & 2.36 \\
\hline
\end{tabular}

Source: results from the DCGE model

The effects of scenarios 1-3 are cumulative, such that the impact of transport policy changes in column 3 should be compared to the results from column 2. By contrast, the adaptation policies in columns 4-6 are run independently of each other and so should each be compared to column 3

affects one sector, then the model responds by reallocating resources towards areas with greater returns according to price signals. However, our previous simulations did not involve any adaptation in the form of policy changes. For example, our results indicate that road damages account for most of the economic cost of climate change. Yet we did not modify transport policy. Railways, for instance, are typically less sensitive to precipitation than roads and can withstand more severe floods. Coastal shipping is also less exposed to flooding, although it is vulnerable to other phenomena such as cyclones.

In this section we explore adaptation options to offset the national welfare losses caused by the most severe global dry climate change scenario. Table 7 presents the adaptation scenarios and their implications for national welfare. The first column reports the average absorption growth rate from the baseline and so is the same for all climate change scenarios. The second column reports climate change impacts and corresponds to Table 6. The remaining columns report results for the adaptation scenarios, which are modeled in three steps. First, we start from the climate change scenarios (column 2) and then adjust transport policies (column 3), thereby reducing the gap in growth rates between climate change and baseline scenarios. The remaining three columns 4-6 contain the effects of the transport policy as well as (1) expanded research and extension to increase the rate of technical progress in agriculture, (2) expanded investment in irrigation infrastructure or (3) enhanced education investment to accelerate human capital accumulation. It is important to note that the final three adaptation policies are undertaken separately (i.e., all results in columns 4-6 should be compared to those in column 3 ).

\section{Adjusting transport policy}

Flooding in the transport sector incurs substantial damages, especially for unpaved roads. $10 \%$ of Mozambique's transport budget is allocated to flood-damaged roads-an allocation that would need to increase under climate change. However, given limited public resources, repairing flood-damaged roads implies lower spending on new road construction and regular maintenance, leading to shorter national road networks under all climate change scenarios (see Table 4). To offset these damages, we consider a change in transport policy that seals unpaved roads granting them resilience to precipitation similar to that of paved roads. We assume that new sealed roads could be constructed for a $10 \%$ increment in construction costs or existing roads sealed during their regular 20-year rehabilitation for a $10 \%$ increment in rehabilitation costs. The dose-response coefficients (i.e., flooding, precipitation and temperature) for paved roads are also applied to sealed (formally unpaved) roads. This shift in design standards is modeled within CLIROAD, and the results are passed down to the DCGE model.

The change in transport policy increases the stock of roads by 2050 under all climate change scenarios (see Table 4). This halves the decline in absorption caused by climate change under the global dry scenario (see Table 7). Moreover, this adaptation scenario assumes that the allocation of public funds to the transport sector remains unchanged from the baseline, implying that reductions in climate change damages are attained without any additional resources. Thus, while networks may be shorter in the near term due to the higher construction and rehabilitation costs of sealed roads, in the long run this is more than offset by the greater climate resilience of the road network. Equally important to note is the slight increase in road coverage even under baseline conditions, which implies that our adaptation policy is advisable even without climate change (i.e., current design standards are suboptimal under historical climate conditions). These findings indicate that adjusting road design standards is a cost-effective, 'no-regret' adaptation option for Mozambique. 
Investing in agriculture and education

The remaining adaptation policies reported in columns 4-6 of Table 7 require additional resources. The maximum resource envelope is derived from the cumulative discounted damages presented in Table 6 for the global dry scenario (i.e., the worst case climate change scenario). The present value of the US\$ 7.4 billion in damages is equivalent to an annual resource transfer equal to about US\$ 400 million. Given this resource envelope, we consider what improvements in agricultural technology, irrigation or human capital investment would be needed to close the remaining gap with the baseline scenario (i.e., each remaining adaptation policy is considered in isolation of the other two).

We find that improving agricultural productivity and human capital accumulation can plausibly close the remaining absorption gap under the global dry scenario. For agricultural research and extension, a 1.2\% acceleration in agriculture's productivity growth rate is sufficient to return absorption to its baseline growth rate of $2.12 \%$ per year in the global dry scenario (see Table 7: column 4). Since global dry is the worst case scenario, improving agricultural productivity raises absorption growth rates above the baseline in other climate change scenarios. This accelerated rate of technical advance is achievable within the maximum budget envelope due to the large gap between Mozambique's high agricultural potential and low attainment. For example, if the elasticity of agricultural productivity growth with respect to public agricultural spending is 0.3 (see Mogues and Benin 2010), then we estimate that the agricultural growth target is achievable for a total US\$ 1.35 billion (discounted at 5\% over 2003-2050). ${ }^{14}$ The cost of this adaptation is well below the value of damages, even in less severe climate change scenarios. Moreover, agricultural intensification is consistent with Mozambique's existing development goals, suggesting that investing in agriculture is also a no-regret adaptation option.

For education policy, we increase the proportion of the workforce that has primary and secondary schooling. More specifically, the annual growth rate of secondary/tertiary educated skilled labor increases by one percentage point (i.e., from about 2 to $3 \%$ per year). Similarly, the growth increment for primary educated semi-skilled labor is 0.8 percentage points, bringing annual growth to $2.3 \%$. Finally, unskilled labor's growth rate declines by 0.6 percentage points in order to maintain the same sized workforce as in the baseline. The scenario is equivalent to about a tenth of the workforce completing primary schooling and is

\footnotetext{
${ }^{14}$ Assuming that government spending remains at ten percent of the GDP and agricultural spending remains at ten percent of the total government budget.
}

sufficient to close the remaining absorption deficit caused by climate change. A detailed costing of this change in education policy is beyond the scope of our study, but appears plausible within a budget considerably less than the maximum US $\$ 400$ million per year. The education scenario also illustrates how it may not be necessary to direct adaptation resources towards damaged areas in order to reclaim the losses caused by climate change. Indeed, more rapid economic development may prove an effective adaptation strategy.

Finally, we increase the amount of irrigated land in Mozambique by more than 1 million hectares. This is equivalent to irrigating about one sixth of cultivated lands by 2050 . We find that this has only little effect on absorption. This is because, as additional lands come under irrigation, the returns to agricultural land and capital decline significantly (i.e., diminishing returns). Without access to foreign markets, the decline in prices caused by rapidly expanding irrigation and agricultural production limits the gains from these investments. Overall, irrigation reduces the damages caused by climate change by US $\$ 0.6$ billion over 2003-2050. This is sufficient to offset the remaining damages from climate change under the local dry scenario (after adjusting transport policies). However, it is far smaller than the additional US\$ 4.9 billion required in the global dry scenario. Irrigation therefore appears to be a less effective means of adapting to climate change in Mozambique.

\section{Conclusion}

Our model results indicate that, without changes in policy, climate change causes economic damages between US\$ 2.3 billion and US\$ 7.4 billion during 2003-2050 (discounted and in 2003 prices). The source of these damages varies across climate change scenarios. A third of damages in the worst case scenario occur during the final decade of our analysis, and are mainly due to flooding and its effect on infrastructure. We find that damages in Mozambique are more related to river basin conditions within Southern Africa than they are to climate patterns within Mozambique itself. Only in the local dry scenario were local precipitation projections more important, with flood frequency declining and agriculture emerging as the primary source of damages.

Each of the climate change scenarios considered here reduces the national welfare. This confirms the need for an adaptation strategy for Mozambique. Using our integrated modeling framework, we identified improved road design standards and agricultural investments as no-regret options. However, uncertainty over climate change scenarios makes it difficult to identify ex ante which other policy changes are required. Accordingly, the best adaptation to climate 
change may prove to be more rapid development leading to a more flexible and resilient society. An effective adaptation strategy should therefore reinforce existing development objectives. Here, our results confirm the importance of human capital. A more educated populace, supported by flexible and competent public and private institutions, will be better able to react to climate changes as they emerge.

While advancing the development agenda is a good adaptation strategy, there are specific policies that emerge as direct responses to climate change. First, our analysis confirms the importance of cooperative river basin management, including the need for regional coordination in designing adaptation strategies. Second, investing in agricultural research and extension is a no-regret option. If climate change redirects resources away from agriculture causing its underlying rate of technical advancement to decline, then large welfare losses are almost inevitable. Third, sealed rural roads may cost more to construct but are more reliable than unpaved roads, and, if properly constructed, cost less over time due to reduced maintenance requirements. Fourth, soft adaptation options can be effective in avoiding damages caused by extreme events. Land use planning is a particularly powerful option since new capital investments over coming decades are likely to exceed already installed capital, which in turn will depreciate well in advance of the main onset of climate change. Finally, hard adaptation options should be carefully scrutinized since, by reducing risk, they may increase exposure to extreme events. For example, building dikes may reduce the probability of storm surges damaging capital, but they will encourage investment behind the dike, and so increase damages when dikes are breeched. Together these adaptation options, while not exhaustive, provide a sound basis for countries like Mozambique to design adaptation strategies that are robust to the uncertainty of climate change.

We conclude by identifying three areas where our analysis and integrated framework could be extended. First, there is considerable uncertainty surrounding the climate change scenarios predicted by different GCMs. Providing ranges of outcomes to governments, as we have done here, is less satisfactory than providing expected outcomes with different confidence intervals. Drawing on the results of probabilistic climate models (see, for example, Sokolov et al. 2009) would thus greatly enhance the robustness of policy prescriptions. Secondly, we have drawn directly from historical climate data, and so our future baseline replicated the sequence of past weather events. However, a stochastic baseline scenario would be less dependent on the historical sequence of (extreme) weather events, but would require greater interaction between biophysical and economic models. Finally, the results from the DCGE model incorporate some autonomous adaptation based on the behavior of representative agents (i.e., producers and consumers). However, these agents do not anticipate climate changes and so do not adjust their behavior based on forward-looking expectations. The extent to which such complex behavior is applicable in the context of climate changes in Africa is an important area for future work.

\section{References}

Allen RG, Pereira LS, Raes D, Smith M (1998) Crop Evapotranspiration: Guidelines for Computing Crop Water Requirements. Irrigation and Drainage Paper 56. FAO, Rome

ANE (2007) Road sector strategy 2007-2011. Administração Nacional de Estradas. Government of Mozambique, Maputo. http://www.ane.gov.mz

Arndt C, Jensen HT, Robinson SR, Tarp F (2000) Agricultural technology and marketing margins in Mozambique. J Develop Stud 37:121-137

Arndt C, Benfica R, Maximiano N, Nucifora A, Thurlow J (2008) Higher fuel and food prices: impacts and responses for Mozambique. Agric Econ 39:497-511

Arndt C, Benefica R, Tarp F, Thurlow J, Uaiene R (2010) Biofuels, growth and poverty: a computable general equilibrium analysis for Mozambique. Environ Develop Econ 15(1):81-105

Block P, Strzepek K (2010) Economic analysis of large-scale upstream river basin development on the Blue Nile in Ethiopia considering transient conditions, climate variability, and climate change. J Water Resourc Plann Manag 136(2):156-166

Dervis K, de Melo J, Robinson S (1982) General equilibrium models for developing countries. Cambridge University Press, London

Dimaranan BV (ed) (2006) Global trade, assistance, and production: the GTAP 6 Data Base Center for global trade analysis. Purdue University, Purdue

Fant C (2009) CLICROP: a one-dimensional model to calculate water stress on crops. Masters Thesis 1460854, University of Colorado at Boulder, pp 122

FAO (2009) FAOSTAT online database. Food and Agriculture Organization of the United Nations, Rome. http://www.fao.org

FAO/IIASA/ISRIC/ISS-CAS/JRC (2008) Harmonized world soil database (version 1.0). FAO, Rome, Italy and IIASA, Laxenburg, Austria

FDOT (2009) Generic Cost Per Mile Models. Florida Department of Transportation, USA. ftp://dot.state.fl.us/LTS/CO/Estimates/CPM/ summary.pdf. Last accessed May 2009

Gupta VK, Sorooshian S (1983) Uniqueness and observability of conceptual rainfall-runoff model parameters: the percolation process examined. Water Resour Res 19(1):269-276

Gupta VK, Sorooshian S (1985) The automatic calibration of conceptual catchment models using derivative-based optimization algorithms. Water Resour Res 21(4):473-486

Hargreaves GH, Allen RG (2003) History and evaluation of hargreaves evapotranspiration equation. J Irrigation Drainage Eng 129(1):53-63

Hinkel J, Klein RJT (2009) The DINAS-COAST Project: developing a tool for the dynamic and interactive assessment of coastal vulnerability. Glob Environ Chang 19(3):384-395

INGC (2009) Estudo Sobre o Impacto das Alterações Climáticas no Risco de Calamidades em Moçambique Relatório Síntese. Instituto Nacional de Gestão de Calamidades, Maputo

Kaczmarek Z (1993) Water balance model for climate impact analysis. Acta Geophys Pol 41:1-16 
Kaczmarek Z (1996) Climate change impacts on the water supply system in the Warta river catchment, Poland. Int $\mathrm{J}$ Water Resourc Develop 12(2):165-180

Lofgren H, Robinson S, El-Said M (2002) A standard computable general equilibrium (CGE) model in GAMS. International Food Policy Research Institute, Washington, DC

McCool C, Thurlow J, Arndt C (2009) Documentation of social accounting matrix (SAM) development. In: Arndt C, Tarp F (eds) Taxation in a low-income economy: the case of Mozambique. Routledge, New York

Meehl GA, Stocker TF, Collins WD, Friedlingstein P, Gaye AT, Gregory JM, Kitoh A, Knutti R, Murphy JM, Noda A, Raper SCB, Watterson IG, Weaver AJ, Zhao Z-C (2007) Global climate projections. In: Solomon S, Qin D, Manning M, Chen Z, Marquis M, Averyt KB, Tignor M, Miller HL (eds) Climate change 2007: the physical science basis. Contribution of working group I to the fourth assessment report of the intergovernmental panel on climate change. Cambridge University Press, Cambridge

Ministry of Energy (2009) Generation master plan for the power sector: volume 1. Report prepared for the Republic of Mozambique by Norconsult, Oslo, Norway

Miradi M (2004) Artificial neural network (ANN) models for prediction and analysis of ravelling severity and material composition properties. In: Mohammadian M (ed) CIMCA 2004. Gold Coast, Australia

Mogues T, Benin S (2010) Public expenditures for agricultural and rural development in Africa. Routledge, New York

Sieben WH (1964) Relation of drainage conditions and crop yields on young light clay soils in the Yssellake Polders. Van Zee tot Land 40

Sieber J, Purkey D (2007) User guide for WEAP21. Stockholm Environment Institute. http://www.weap21.org
Sokolov AP, Stone PH, Forest CE, Prinn R, Sarofim MC, Webster M, Paltsev S, Schlosser CA, Kicklighter D, Dutkiewicz S, Reilly J, Wang C, Felzer B, Melillo JM, Jacoby HD (2009) Probabilistic forecast for twenty-first-century climate based on uncertainties in emissions (without policy) and climate parameters. J Clim 22(19):5175-5204. doi:10.1175/2009JCLI2863.1

Strzepek K, Balaji R, Rajaram H, Strzepek J (2008) A water balance model for climate impact analysis of runoff with emphasis on extreme events. Report prepared for the World Bank. World Bank, Washington, DC

Tarp F, Arndt C, Jensen HT, Robinson SR, Heltberg R (2002) Facing the development challenge in Mozambique: a general equilibrium perspective. Research Report 126. International Food Policy Research Institute, Washington, DC

Thurlow J (2004) A dynamic computable general equilibrium (CGE) model for South Africa: extending the static IFPRI Model. Working Paper 1. Pretoria: Trade and Industrial Policy Strategies

World Bank (2009a) Mozambique: economic vulnerability and disaster risk assessment. World Bank, Africa Region, Washington, DC

World Bank (2009b) The costs to developing countries of adapting to climate change: new methods and estimates, global report of the economics of adaptation to climate change study. World Bank, Washington, DC

World Bank (2010a) Economics of adaptation to climate change: Mozambique case study, country report of the economics of adaptation to climate change study. World Bank, Washington, DC

World Bank (2010b) World development indicators database. World Bank, Washington, DC. http://www.worldbank.org

Yates DN (1996) WatBal: an integrated water balance model for climate impact assessment of river basin runoff. Int $\mathrm{J}$ Water Resourc Develop 12(2):121-139 